\title{
Fracture of the femur in children
}

In the past, all isolated and uncomplicated fractures of the femoral shaft in children were managed conservatively. Recent advances in external and internal fixation have changed this pattern and promoted animated debate about the indications for and the methods of surgery. Any decision to operate on this fracture in a child requires very careful analysis in terms of convenience, cost and complications.

First, the convenience of primary operation. Provided that good facilities are available, surgical stabilisation may be justifiable, not only for the child and its family, but also to help nursing and medical staff to care for a fracture which may not behave satisfactorily in a Thomas splint or a plaster spica. In this issue of the Journal Bar-On et al (p. 975) suggest that fixation by flexible nails is appropriate for patients over the age of five years, but their prospective study would have been more convincing if it had included a conservatively-managed control group. Fixation by flexible rods, plates or external fixators requires one, and often two, general anaesthetics, and a total use of theatre time approaching or exceeding two hours. By contrast, the use of regional anaesthesia for the femoral nerve allows the application of skin traction in a Thomas splint without the time and risks of general anaesthesia and an open operation. Management in a hip spica, either acutely or after an initial period of traction, needs only a single general anaesthetic. Conservative treatment may require more time in hospital but less in the operating theatre.

The convenience of only one week in hospital is attractive to the family and to a child who can cope with swift rehabilitation, but social circumstances may outweigh the advantages of early discharge. The wide range of time before returning to school, reported to be from three to 32 weeks in the study of Bar-on et al, confirms that the personalities of both the fracture and the child have a considerable influence. Rapid discharge must take account of parental competence; return to school may not be hastened by the intramedullary rod!

Secondly, cost is now an important factor. Newton and Mubarak $^{1}$ found that the early application of a hip spica was the cheapest option, although effective only in younger

M. F. Macnicol, MCh, FRCS Ed Orth, Consultant Orthopaedic Surgeon The Royal Hospital for Sick Children, 9 Sciennes Road, Edinburgh EH9 1LP, UK.

(C) 1997 British Editorial Society of Bone and Joint Surgery 0301-620X/97/68376\$2.00

J Bone Joint Surg [Br] 1997;79-B:891-2. children. The use of traction or intramedullary rodding was considerably more expensive, but the cost of treating an adolescent patient conservatively was $50 \%$ greater than that of early surgical fixation, largely because of a threefold difference in mean hospital stay. Finance must not be allowed to dictate the principles of clinical care, but early operative treatment does seem to benefit all concerned in the management of difficult fractures in older children. For other cases, the budgetary advantages of operative intervention are less convincing, particularly when treatment by traction at home can be competently organised.

Thirdly, the potential for complications is important, especially any which may lead to a lasting disability. In a child, minor malunion is of little concern provided that it does not include a large rotational deformity. In this respect, internal fixation is more certain to achieve an acceptable reduction than either external fixation or splintage. Long-term reviews of remodelling such as that of Wallace and Hoffman ${ }^{2}$ show that an initial angular deformity of even $25^{\circ}$ can recover to give normal function. Overgrowth is more likely after an operation, although the importance of length discrepancy may have been overrated unless it reaches $2 \mathrm{~cm}$ or more. Knee stiffness may complicate the results after external fixation at least temporarily. The use of intramedullary rods introduces the unique dangers of epiphysiodesis of the greater trochanter and of avascular necrosis of the femoral head. Raney, Ogden and $\mathrm{Grogan}^{3}$ report five patients with premature closure of the physis of the greater trochanter after intramedullary nailing: they all developed increased valgus of the femoral neck and one had mild radiological subluxation of the hip. O'Malley, Mazuk and Cummings ${ }^{4}$ reported avascular necrosis of the femoral head after closed intramedullary nailing with a locking nail. This disastrous potential should make surgeons think very hard before using this type of fixation in skeletally immature patients.

These serious complications are infrequent, as is the major one of deep infection, but they result only from the use of implants. The flexible, paired nail system described by Bar-On et al reduces these risks, but may produce symptoms at the sites of nail insertion. Refracture may occur after either conservative or operative treatment, and a review of the orthopaedic literature on this feature provides no unequivocal evidence.

The availability of flexible nails and the attractions of early definitive surgery must not blind surgeons to the adequacy and proven value of the skilled conservative management of fractures of the femoral shaft in children under ten years of age. The complications, cost and convenience of any new method must be carefully evaluated. 
Information on the advantages of fixation is helpful, but all decisions must be tempered with a concern to do no harm.

MALCOM F. MACNICOL

\section{REFERENCES}

1. Newton PO, Mubarak SJ. Financial aspects of femoral shaft fracture treatment in children and adolescents. J Pediatr Orthop 1994;14: 508-12.
2. Wallace ME, Hoffman EB. Remodelling of angular deformity after femoral shaft fractures in children. J Bone Joint Surg [Br] 1992; 74-B:765-9.

3. Raney EM, Ogden JA, Grogan DP. Premature greater trochanteric epiphysiodesis secondary to intramedullary femoral rodding. $J$ Pediatr Orthop 1993;13:516-20.

4. O'Malley DE, Mazuk JM, Cummings RJ. Femoral head avascular necrosis with intramedullary nailing in an adolescent. $J$ Pediatr Orthop 1995;15:21-3.

\section{Planovalgus and cavovarus deformity of the hind foot}

A functional approach to management

To function correctly the foot and ankle require articular stability and normal alignment. The talus occupies a key position since it has no muscle attachments and $70 \%$ of its surface is covered by articular cartilage. Its stability depends on ligaments and the action of extrinsic and intrinsic muscles.

Many deformities of the foot arise in the hind foot; both varus and valgus may be caused by imbalance of the extrinsic muscles. In a child the capacity for bone and articular remodelling may allow correction by soft-tissue release and tendon transfers, but in an adult bony procedures are required.

\section{MORPHOLOGICAL PRINCIPLES}

A comparison of the hip with the joints of the hind foot shows similarities. ${ }^{1,2}$ The hip is a ball-and-socket joint or 'enarthrosis' as is the talocalcaneonavicular joint. ${ }^{3}$ Principles already well-established for the management of hip deformities could be effective for deformities of the hind foot.

In the hip the femoral head lies against the concave cartilaginous surface of the acetabulum. This is part of a sphere with a horseshoe-shaped articular surface, consisting of the pubis anteriorly, the ilium superiorly and the ischium posteriorly. When these bones fuse in adolescence, the ischial and pubic parts remain linked inferiorly by the strong transverse ligament. ${ }^{4}$

In the foot, the head of the talus lies against a concave

K. Klaue, MD, Associate Professor

ATOS Klinik, Department of Orthopaedic Surgery, Bismarckstrasse 9-15, 69115 Heidelberg, Germany.

(C)1997 British Editorial Society of Bone and Joint Surgery 0301-620X/97/67195 \$2.00

J Bone Joint Surg [Br] 1997;79-B:892-5. cartilaginous surface which is also horseshoe-shaped. The navicular facet lies anteriorly, the anterior facet of the calcaneum is in the middle, and the sustentaculum tali supports the talus inferiorly and posteriorly. Laterally, these structures are bound together by a section of the ligamentum bifurcatum, and below by the spring ligament between the navicular and the sustentaculum tali. The talocalcaneonavicular joint is therefore also a ball-andsocket joint which allows mobility in the frontal plane. Its functional anatomy is similar to that of the hip.

Distal to this ball and socket, the anatomy of the foot can be considered as consisting of medial and lateral columns. The medial column is analagous to the 'femoral' part of the combined joint. Its socket, the calcaneonavicular cup, continues as the three cuneiforms, the three first metatarsals, and the corresponding toes. The lateral column comprises the calcaneum, the cuboid, and the two lateral rays. The function of the subtalar joint depends on the division of load between these columns, and any imbalance will cause deformity.

Loss of movement proximally as a result of triple arthrodesis may lead to abnormal movement and degenerative changes in the neighbouring joints, the ankle and the joints of the midfoot. ${ }^{5}$

\section{PATHOLOGY}

The principal deformities of the hind foot are varus-cavusadductus (club foot) and valgus-planus-abductus (flat foot).

Varus deformity. In the hip, acetabular dysplasia reduces the cover of the femoral head, and in children progressive plastic deformation may remodel the cavity from its normal cotyloid shape into an ovoid. ${ }^{6}$ A similar deformation may occur in club foot due to prenatal muscle imbalance. ${ }^{7}$ In the frontal plane the head of the talus moves laterally and the calcaneonavicular cup becomes an ovoid. The forefoot inclines medially, creating a talometatarsal angle which is 